\title{
Estudio sobre la creación y desarrollo del cortometraje y del vídeo documental en el entorno actual - Líneas del tiempo
}

\section{Study on the creation and development of the short film and documentary video in the current environment - Líneas del tiempo}

\author{
Jianxiong Liu/刘剑雄 \\ Universidad de Granada \\ daxiong-liu@hotmail.com
}

Recibido 31/08/2020 Revisado 09/10/2020

Aceptado 09/10/2020 Publicado 30/04/2021

\section{Resumen:}

El 2020 está siendo un año plagado de incertidumbres. El virus Covid-19 ha arrasado el mundo, afectado enormemente a las relaciones interpersonales y al tejido económico e industrial de todos los países. Por supuesto, España y China también se han visto perjudicadas, y algunas de sus industrias se han estancado o, incluso, han retrocedido. Sin embargo, con el desarrollo de la tecnología y de la información, el uso de los vídeos de corta duración se ha integrado en todos los ámbitos de nuestras vidas, rompiendo las limitaciones temporales y espaciales.

Gracias a su inmediatez, brevedad, diversidad de temas y a los múltiples canales de difusión, el formato vídeo se ha asentado en las plataformas virtuales, despertando el interés de la población más joven y activa en las redes sociales y convirtiéndose en una manera muy habitual para divulgar contenidos.

Durante estos meses de confinamiento y las posteriores fases de desescalada, grabé imágenes de como el Covid-19 afectó al comportamiento de diferentes personas. Con este material, he realizado la pieza de video "Líneas del Tiempo".

En mi opinión, a causa de la epidemia de Covid-19, la difusión de la información en red y la comunicación online se han convertido en una parte inseparable de nuestras vidas. Tal vez la utilización de estos nuevos medios, como herramienta para desarrollar las propuestas creativas y comunicarnos sin limitaciones geográficas, puedan ser una posibilidad para este tiempo de incertidumbre.

\section{Sugerencias para citar este artículo,}

Liu, Jianxiong (2021). Estudio sobre la creación y desarrollo del cortometraje y del vídeo documental en el entorno actual-Líneas del tiempo. Tercio Creciente (Monográfico extraordinario V), (pp. 49-60), https://dx.doi.org/10.17561/rtc.extra5.5719

LIU, JIANXIONG. Estudio sobre la creación y desarrollo del cortometraje y del vídeo documental en el entorno actual-Líneas del tiempo. Tercio Creciente (Monográfico extraordinario V) abril 2021, pp. 49-60, https://dx.doi.org/10.17561/rtc.extra5.5719 


\section{Abstract:}

2020 continues the be a year full of uncertainties. The Covid-19 virus has devastated the world, greatly affecting interpersonal relationships and the economic and industrial fabric of all countries. Of course, Spain and China have also been affected and some of their industries have stagnated or even regressed. However, with the development of technology and information, the use of short videos has been integrated into all areas of our lives, breaking the limitations of time and space.

Thanks to its immediacy, brevity, diversity of topics and multiple sharing channels, the video format has established itself on virtual platforms, awakening the interest of the youngest and most active population on social networks and becoming a very common way to spread content.

During these months of confinement and the subsequent de-escalation phases, I recorded images of how covid-19 affected the behavior of different people. This material is the subject of my video "Líneas del tiempo".

In my opinion, because of the Covid-19 pandemic, the spread of network communication has become an essential part of our lives. Perhaps the use of these new media as a method to develop creative offers and communicate without geographic limitations could be a possibility to draw upon during this time of uncertainty.

\section{Palabras Clave:}

Covid-19; Cortometraje; Tecnología 5G

\section{Key words:}

Covid-19; Short Film; 5 G technology

Sugerencias para citar este artículo,

Liu, Jianxiong (2021). Estudio sobre la creación y desarrollo del cortometraje y del vídeo documental en el entorno actual-Líneas del tiempo. Tercio Creciente (Monográfico extraordinario V), (pp. 49-60), https://dx.doi.org/10.17561/rtc.extra5.5719

LIU, JIANXIONG. Estudio sobre la creación y desarrollo del cortometraje y del vídeo documental en el entorno actual-Líneas del tiempo. Tercio Creciente (Monográfico extraordinario V) abril 2021, pp. 49-60, https://dx.doi.org/10.17561/rtc.extra5.5719 


\section{Introducción}

\subsection{Contenido del vídeo}

El 2020 está siendo un año inusual. Con la llegada del Covid-19, la vida de las personas ha experimentado cambios trascendentales. El cortometraje "Líneas del tiempo" es un video documental con una duración de 6 minutos y 15 segundos, cuyo contenido principal es el registro de la vida del autor durante la cuarentena en España.

El vídeo está dividido en cuatro capítulos, según las etapas de prevención de la epidemia española. La primera etapa es la cuarentena de aislamiento domiciliario, durante los meses de marzo, abril y mayo. El contenido principal de este segmento es la vida del autor en su hogar y lo que puede ver alrededor de su casa. La imagen obtenida es una combinación de fotografía y vídeo que han sido editadas siguiendo un orden cronológico. El argumento narra en primera persona la vida cotidiana del autor, los pequeños cambios, la vista desde su balcón, las hojas que caen y las flores que brotan durante el tiempo de la cuarentena.
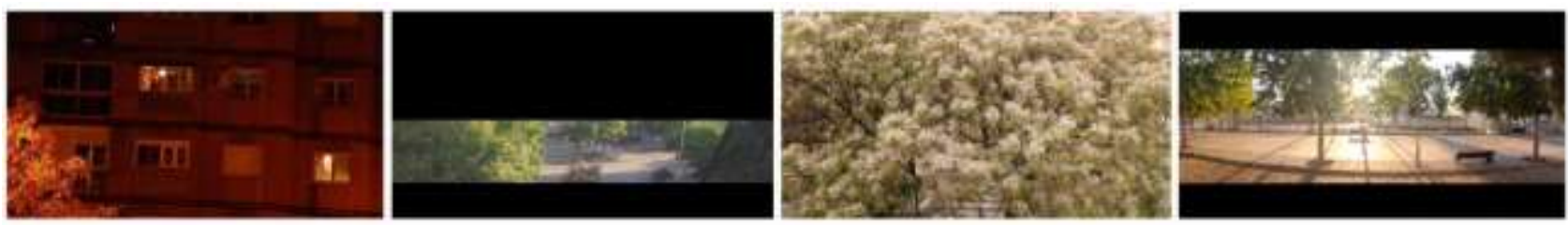

Ilustración 1 Las imágenes del vídeo

El segundo capítulo se corresponde con la segunda fase de la desescalada, momento en el que era posible salir a la calle con limitaciones horarias. El vídeo documenta las actividades del autor al salir de su casa. Se utiliza el paso de la noche al día como alegoría de un estado interior, que oscilaba desde el miedo a la epidemia hasta la esperanza de que termine pronto.
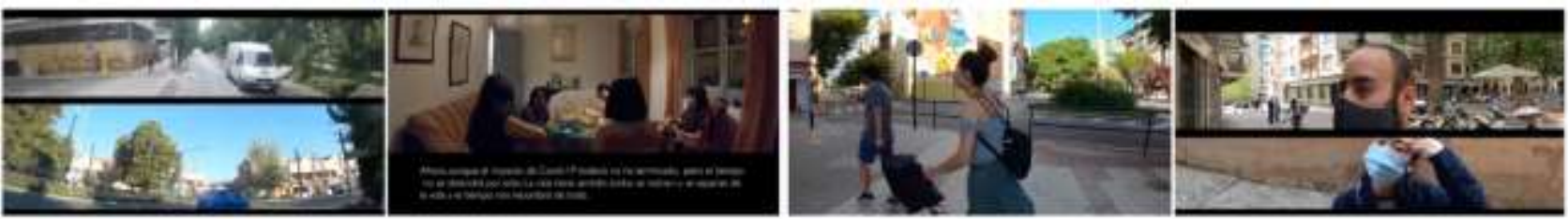

Ilustración 2 Las imágenes del vídeo 
El siguiente capítulo del vídeo se refiere a la tercera etapa de la desescalada. En este caso utilizo la aceleración de la imagen para registrar la vida en la ciudad de Granada. En este momento ya se puede salir y visitar a otras personas. Este capítulo también registro mi primera cena con amigos en el final de esta fase de la cuarentena, en el mes de junio. El propósito es mostrar como la vida de los españoles está volviendo poco a poco a una "anormal normalidad.

El último capítulo del vídeo es el denominado "Futuro". El contenido de este capítulo son pequeños fragmentos felices y cotidianos de la vida de diferentes personas, resultando positivo y optimista, lo que juega un papel en la sublimación del tema, pues hasta ahora la vida de los habitantes sigue estando afectada por el Covid-19, por eso en el vídeo final se presenta un deseo positivo del autor: quiere que todo vuelva a la normalidad.

La música del cortometraje, que juega un papel en la conducción de las emociones, también ha sido realizada por el auto, utilizando una aplicación simulación de piano Steway.

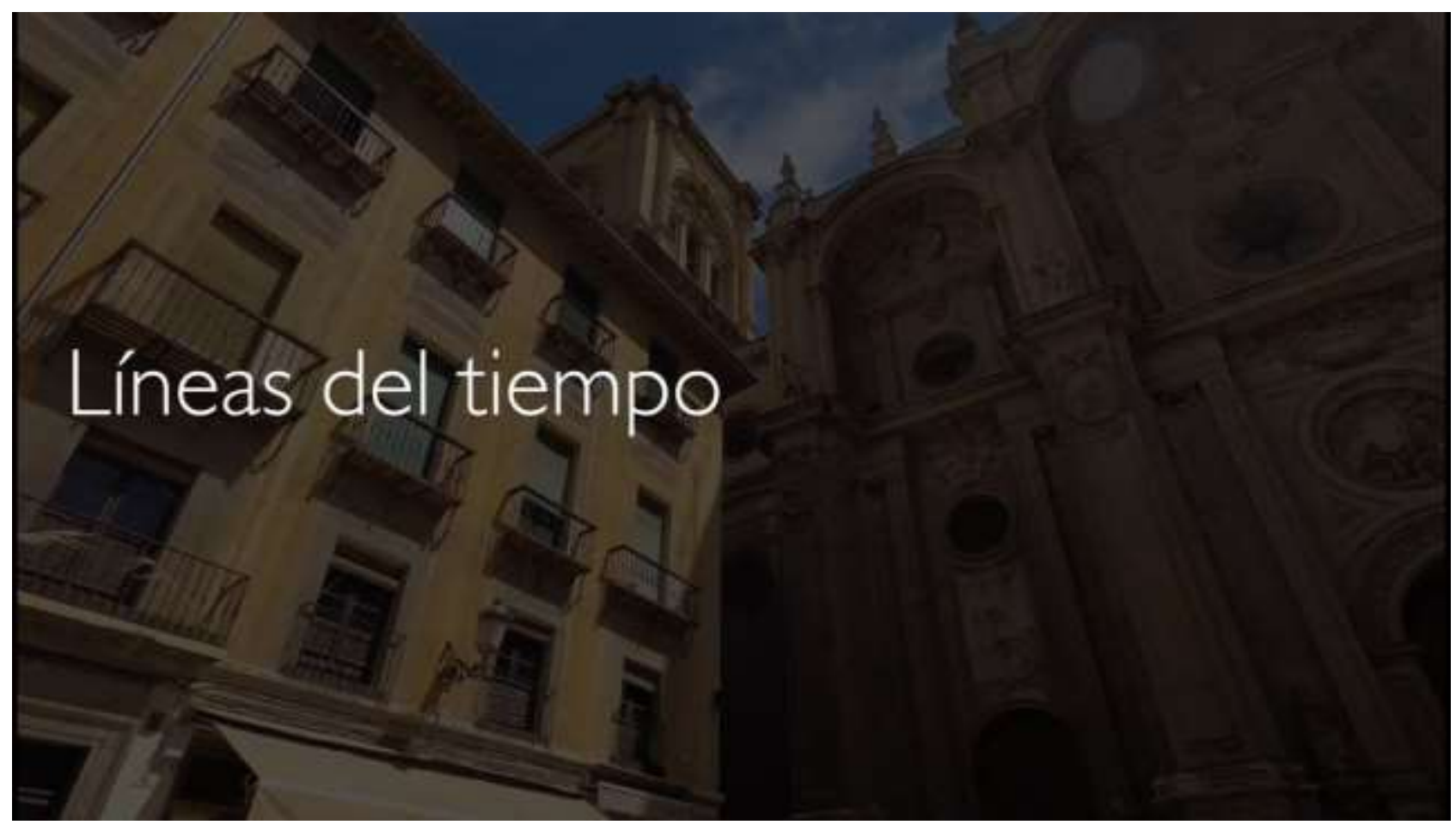

El enlace del vídeo: https://www.youtube.com/watch?v=yd15-NOcDlg 


\subsection{Objetivo}

Este trabajo forma parte de las actividades de la investigación doctoral que actualmente estoy realizando. Esta investigación, perteneciente al programa de doctorado en Historia y Artes en la Universidad de Granada, se centra en el estudio de las sociedades china y española, intentando establecer analogías y diferencias basándonos en el comportamiento de la población estudiantil. Este año 2020 es un año conflictivo y extraordinario, porque España y el mundo se han visto influenciados por el Covid-19. La vida del autor también ha cambiado mucho, por eso creó "Líneas del tiempo", un cortometraje artístico que se mezcla con el pensamiento subjetivo del autor y además tiene carácter documental, ya que su propósito es grabar estos días únicos. El contenido del vídeo tiene una característica temporal: por ejemplo, al comienzo de este hay personas que aplauden desde sus ventanas por la ventana a los médicos que están luchando contra la epidemia, y también hay imágenes de personas con mascarillas en la calle. Estos estilos de vida anormales muestran la particularidad de este período de tiempo, teniendo valor de registro y de investigación. Las plataformas de publicación de este cortometraje son los sitios web YouTube y Bilibili, y su publicidad y comunicación se logra a través de estas famosas plataformas de vídeos en oriente y occidente.

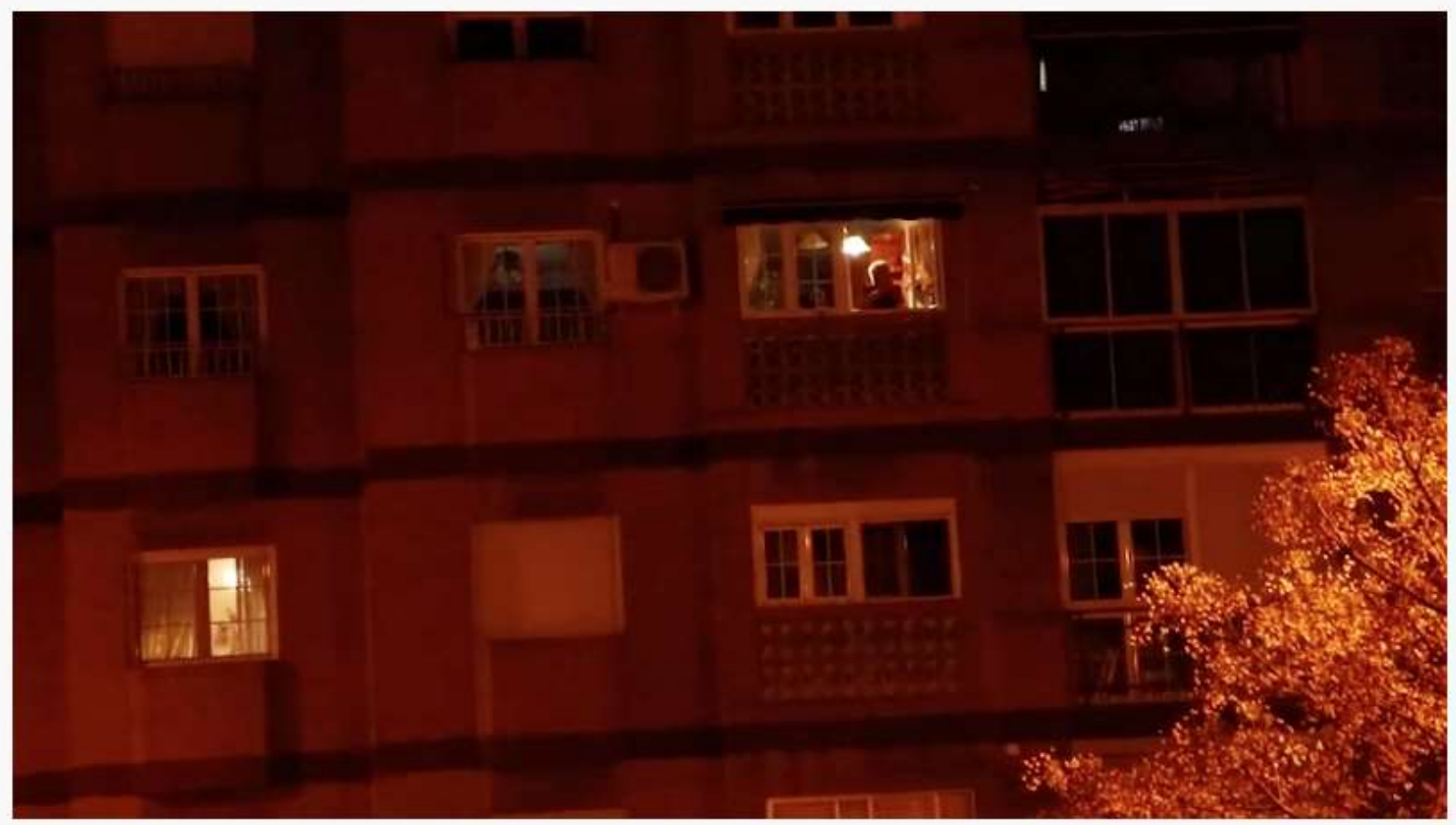

Ilustración 3 Imagen del vídeo: La gente aplaude desde su ventana 


\subsection{Producción}

En el cortometraje "Líneas del tiempo", las herramientas de filmación utilizadas son una cámara (la Canon EOS 800D) y una cámara GoPro 8, editadas y sintetizadas por Adobe Premiere. Los métodos de rodaje fueron la perspectiva en primera y tercera persona, utilizando la secuencia del tiempo, el montaje y el ajuste de la velocidad del tiempo para narrar el contenido.

La música del vídeo es sintetizada por el autor a través del contenido de la pantalla de vídeo, tocando los instrumentos una vez finalizada la edición para lograr que la música y la imagen encajen bien.

El tiempo de producción de todo el cortometraje duró 4 meses, y el campo de rodaje cubre todas las partes de Granada. Es un cortometraje artístico, contemporáneo y documental que refleja el punto de vista personal del autor.

\subsection{El significado de la producción de video}

Con el desarrollo de los tiempos, el ritmo de vida de las personas se ha acelerado gradualmente. La llegada del coronavirus ha detenido la ajetreada y vertiginosa vida moderna. La llegada de la epidemia ha sido como una guerra silenciosa que ha acabado con la vida de innumerables personas y ha paralizado al país. Las personas se han visto obligadas a aislarse en casa y vivir una vida completamente diferente a la habitual. Muchas industrias no podían operar como lo hacen normalmente, pero la industria de Internet se ha convertido en una ventana para que las personas se comuniquen y comprendan al mundo. Por esta razón, los vídeos de corta duración, que son productos emergentes de Internet, han ido apareciendo poco a poco en nuestras vidas.

Para los creadores y artistas, la llegada de Covid-19 no sólo significó un desastre, también puede entenderse como una oportunidad. La creación comienza con una renovada visión y nuevas herramientas. La riqueza del cortometraje y sus propias características se pueden utilizar como una nueva forma de comunicación y creación, que puede hacer que estas sigan la tendencia de los tiempos y obtengan un mayor desarrollo. 


\section{El Desarrollo del Cortometraje}

Las plataformas donde el autor publicó "Líneas del tiempo" son YouTube y Bilibili. Esas han tenido un gran impacto en los países occidentales y China, respectivamente. A través de la difusión del vídeo, el autor ha tenido la oportunidad de participar en "I CIVARTES 2020 / Congreso Internacional Virtual de artes". En el segundo capítulo de este artículo, vamos a entender mejor acerca del cortometraje (como técnica y medio de comunicación) y su desarrollo, las ventajas y desventajas del desarrollo de la tecnología de vídeo para creadores en el entorno del 2020.

Con el desarrollo de la tecnología de la información y la popularización de Internet y la tecnología 4G, han surgido muchas industrias y novedades en el sector. Los vídeos de corta duración son una de esas novedades. Como producto nacido del desarrollo de la tecnología de la información, estos vídeos pueden llenar el tiempo fragmentado de los usuarios.

Las particularidades de estos vídeos se pueden dividir en los siguientes cuatro aspectos:

1. Tienen las características de UGC (contenido producido por el usuario). El Grupo de Cooperación y Desarrollo Económicos (OCDE) define UGC como "Un contenido disponible públicamente, producido por aficionados a través de canales no profesionales, que contiene una cierta cantidad de trabajo creativo y ha sido reproducido"1.

2. En segundo lugar, es fácil de hacer, corto y fácil de compartir.

3. En tercer lugar, tiene fuertes atributos sociales.

4. Por último, existen muchos canales de comunicación y una fuerte respuesta de la audiencia.

Combinando los rasgos anteriores, el vídeo corresponde a las necesidades vitales aceleradas y fragmentadas de la contemporaneidad. A través del video, las personas pueden obtener materiales e imágenes frescas de primera mano rápidamente. Hoy en día, los vídeos de corta duración se han convertido en la mejor publicidad y promoción en la época contemporánea, siendo una tendencia importante en la vida moderna.

\footnotetext{
${ }^{1}$ Graham Vickery, Sacha Wunsh-Vincent (2007), Participative Web and User- Created Content; Web 2.0, Wikis and Social Networking. Paris [M]: Organization for Economic Cooperation and Development (OECD)
} 


\subsection{Antecedentes del cortometraje}

Hoy hemos entrado en la época de la información digital. La aplicación y el desarrollo de Internet han provocado cambios tremendos en la vida y entretenimiento de las personas. El método tradicional para conectarse a Internet, que implicaba el uso de terminales de computadora para PC ha comenzado a declinar, y la popularidad de los teléfonos inteligentes y tabletas ha aumentado aún más el número de usuarios.

El aumento de la cantidad de usuarios con teléfonos inteligentes, la popularización de la tecnología 4G y el soporte de plataformas de distribución, han hecho que el mercado global de vídeos cortos se desarrolle rápidamente y se convierta en una tendencia importante en la era actual. Debido a la innovación tecnológica, se han mejorado la audiencia de vídeo móvil y los problemas de calidad. En el pasado, los vídeos largos tenían una visualización relativamente grande y, al mismo tiempo, tenían altos requisitos de calidad de imagen, lo que dificultaba su portabilidad. El vídeo corto compensa esta deficiencia, y su demanda de audiencia y calidad son menos limitadas que el largometraje. También, la mejora de la tecnología de hardware móvil ha hecho posible procesar vídeos en el teléfono móvil. Las personas pueden editar y procesar sus propios vídeos en sus teléfonos fácilmente, lo que promueve el desarrollo y actualización de plataformas que se dedica a este tipo de contenido.

\subsection{El impacto de los vídeos de corta duración}

Con la aceleración del ritmo de vida, cada vez más jóvenes se inclinan por la lectura de textos muy breves, apenas titulares o los caracteres de un twitt. Con el aumento de usuarios de teléfonos móviles y el auge de las plataformas de vídeos cortos y/o cortometrajes, su influencia es cada vez más grande en nuestras vidas. Desde la aparición de YouTube en los Estados Unidos en 2005, hasta la aparición de varias plataformas de vídeos como Instagram y Tiktok, han hecho que cada vez haya más de vídeos cortos, plataformas y canales de difusión. Utilizando un teléfono inteligente normal puede producirse de forma independiente estos vídeos. Para las personas involucradas en la industria del arte, esta es también una nueva forma de creación y promoción de arte. Este método requiere solo una pequeña cantidad de inversión y se puede realizar con equipos comunes (teléfonos móviles, cámaras y otros equipos de fotografía). Esta es la razón por la que YouTube, Instagram y Tiktok se han vuelto populares en los últimos años. La gente puede editar, crear, cargar y compartir vídeos personales en estas plataformas. Este nuevo formato ahorra mucho tiempo y dinero a los creadores. 
Bajo la influencia de Covid-19 en 2020, el funcionamiento de las plataformas del internet seguirá desarrollándose a mayor velocidad cuando otras industrias se hayan estancado o incluso retrocedido. El desarrollo de vídeos y/o cortometrajes nos ha brindado nuevas oportunidades y nos ha proporcionado nuevos métodos de creación y plataformas de comunicación más convenientes para los creadores de arte. Con el desarrollo de la era de la información, tendrán un gran impacto en

el futuro.

\subsection{La orientación del video corto en el futuro}

El autor tiene una visión optimista sobre el desarrollo futuro de cortometrajes. Hoy en día, las principales plataformas de vídeos se están desarrollando rápidamente y se influyen mutuamente, habiendo cada vez más tipos de estos vídeos. Como producto emergente del desarrollo de la tecnología de la información, los vídeos de corta duración tienen una gran vitalidad y variedad. Por este motivo, han surgido muchas profesiones nuevas, como Youtuber, Instagramer e Influncer, que dependen de una fuerte audiencia para generar ingresos rentables e impactar gradualmente en su sociedad.

En 2020, China ha entrado oficialmente en la época de la tecnología de comunicación 5G. Los vídeos cortos hechos con móviles surgieron en la era 4G, pero recién ingresaron a la etapa de crecimiento con la tecnología 5G. Hoy, en China, el papel del 5G en el desarrollo de la industria de los medios es cada vez más evidente. Sus ventajas de alta velocidad, baja latencia, bajo consumo de energía y bajo costo, hacen que la gente sea la mayor beneficiaria de esta revolución tecnológica. 


\section{Época IP personal del creador}

En la actualidad, la tecnología 5G China ha estado a la vanguardia del desarrollo de la tecnología de la información en el mundo. La llegada del 5G ha provocado el auge de los vídeos y la mejora de la industria de auto-media, y estos están estrechamente vinculados. Los productores de contenido utilizan vídeos de corta duración para atraer la atención de los aficionados, establecer "IP personal" 2 y, a través de la auto-promoción con los medios de comunicación, generar ingresos económicos.

"IP personal" es una definición amplia, que encarna el valor de la producción de los individuos, y es una nueva forma de difundir a través de Internet para tener impacto. Es una fuente de recursos de propiedad intelectual, y también es una dirección de red IP que atrae fanáticos y visualizaciones. Es una integración de toda la cadena de la industria. También puede definirse como las celebridades de Internet, marcas, etc. (Dandan Li y Xinyu Zhou, 2020: 7), lo que se conoce como "influencer".

Hoy en día, todo el mundo puede convertirse en un IP. El valor personal se puede transmitir a través del Internet, y la cantidad de visualizaciones puede ser mayor a través de la influencia personal, a fin de lograr el propósito de convertir estas visualizaciones en ingresos. Hoy en día, "auto-media" se ha convertido en la posición principal para el desarrollo de plataformas de vídeo. Entre ellos, el papel de vídeos cortos es indispensable. Por esta razón, como creador, se debe mejorar el contenido creativo, la eficiencia operativa y hacerse una IP, persona influyente o "influencer".

\section{Variedad de videos de corta duración}

Después del surgimiento de la tecnología de comunicación 4G, la difusión de contenido se actualizó, pasando de los libros de papel tradicionales y las pantallas de televisión a Internet, e ingresando después a los teléfonos móviles de las personas. La forma en que las personas ven vídeos no se limita a los interiores de la casa, y ya incluso colaborar con los creadores vía online. La interacción comienza a marcar el comienzo de una época en la que todos pueden crear. La tecnología 5G cambiará la atención de las personas, dejando las pantallas de los móviles para atender a otros aspectos de la vida. En ese momento, la realidad virtual (VR), la realidad aumentada (AR), el $4 \mathrm{~K}$ y otras tecnologías ya no estarán limitadas por la velocidad de transmisión de la red y la popularización de las nuevas tecnologías. También se promoverá la difusión de la cultura y el arte a mayor escala.

\footnotetext{
${ }^{2}$ Hasta ahora no hay una definición precisa de "IP personal".
} 
Los creadores pueden utilizar la tecnología de Internet, y sus métodos creativos no se tienen que limitar a la creación individual. La función interactiva de la plataforma de vídeos de corta duración se convertirá en un puente entre creadores y espectadores.

\subsection{Análisis de las ventajas y desventajas del desarrollo de videos cortos en la nueva época}

El siglo XXI es la época de la tecnología de la información. El funcionamiento a alta velocidad de la tecnología de la información ha superado las limitaciones de tiempo y espacio. Bajo la influencia de Covid-19 en 2020, la difusión de vídeos cortos comenzó a aparecer gradualmente e integrarse en la vida de las personas. Gracias a sus propias características, se extiende rápidamente entre la multitud y la gente puede captar las noticias en tiempo real o mucho más rápido que antes. En segundo lugar, los atributos de entretenimiento de estos vídeos pueden liberar el estrés mental de las personas. Los botones de los gustos como Like y Dislike, los comentarios y los mensajes privados en las plataformas de vídeos dan al público no solo la oportunidad de expresar sus opiniones, sino también satisfacer sus necesidades sociales. Con el advenimiento de la era 5G de China, cada vez más personas utilizarán vídeos o cortometrajes para satisfacer sus necesidades de entretenimiento, aprendizaje, redes sociales y acceso a la información. Su desarrollo diversificado traerá más oportunidades para más creadores.

Hoy en día, cada vez aparecen más youtubers, Instagramers e influencers. Ellos atraen la atención de una gran cantidad de personas, y estos seguidores les generan enormes ganancias. Los creadores usan esto como un incentivo y hacen más vídeos. En esta época en la que las visualizaciones de la red pueden convertirse en ingresos, los vídeos de corta duración han brindado más oportunidades y posibilidades a los creadores.

Por supuesto, todo tiene dos aspectos. En esta época de intercambio de recursos basados en información, la cantidad de vídeos cortos se incrementará de manera explosiva, y es inevitable que algunos vídeos no se ajusten a las normas. Bajo la atracción de intereses económicos, estarán llenos de violencia, pornografía o contenido que atente contra la ética social. Por ello, la supervisión y gestión de la plataforma se enfrenta a severos desafíos. Ahora, el entretenimiento es uno de los principales atributos estos vídeos. La afluencia de demasiados vídeos de entretenimiento a las principales plataformas dará como resultado un desarrollo desequilibrado de la composición del contenido. La calidad de los vídeos será desigual y las funciones de educación, difusión de información y economía se verán afectadas. 
ISSN: $2340-9096$

https://doi.org/10.17561/rtc.extra5.5719

(अ)

\section{Conclusiones}

La llegada de la nueva época está cambiando gradualmente nuestras vidas. Bajo la influencia de Covid-19, Internet ha jugado un papel cada vez más importante en nuestras vidas. El vídeo corto es un nuevo producto del desarrollo de la tecnología de la información, que nos da nuevas oportunidades para la creación y la difusión. "Líneas del tiempo" es solo un cortometraje documental artístico, pero el significado detrás de él y el desarrollo de medios de la nueva era que representa atraerá la atención de más personas.

\section{Referencias}

[1] Graham Vickery, Sacha Wunsh - Vincent, Participative Web and User- Created Content; Web 2.0, Wikis and Social Networking. Paris [M]: Organization for Economic Cooperation and Development (OECD), 2007.

[2] 李丹丹，周芯宇，浅析 $5 \mathrm{G}$ 时代移动短视频的发展 $[\mathrm{J}]$ ，数字传媒研究，2020年，第7 期。

[2] Dandan Li, Xinyu Zhou, Analysis of the development of mobile short video in the $5 \mathrm{G}$ era [J], Digital Media Research, 2020, 7 : 7. 